\title{
Deferasirox in pyruvate kinase deficiency
}

\author{
Dries Deeren
}

Received: 5 September 2008 /Accepted: 10 September 2008/Published online: 23 September 2008

(C) Springer-Verlag 2008

\section{Dear Editor,}

In a recent article in Annals of Hematology, Metzgeroth and colleagues reported the effects of oral iron chelation therapy with deferasirox in myelodysplasia patients with transfusion-related iron overload [1].

Patients with other blood disorders with complications of iron overload may also benefit from deferasirox.

We report the case of a 40-year-old woman with pyruvate kinase deficiency who was referred because of fatigue. She had a history of severe haemolysis requiring frequent red cell transfusions. Twenty years earlier, she underwent cholecystectomy and splenectomy after which the transfusion requirement was abolished and the haemoglobin level was stable at $9.5 \mathrm{~g} / \mathrm{dl}$. Now, the ferritin level was $4,500 \mu \mathrm{g} / \mathrm{l}$, aspartate aminotransferase $169 \mathrm{U} / 1$, alanine aminotransferase $147 \mathrm{U} / 1$ and gamma glutamyltransferase $96 \mathrm{U} / 1$. The black hypointense liver on magnetic resonance imaging confirmed iron overload. There were no cardiac abnormalities. She was heterozygous for the His63Asp mutation of the HFE gene.

Deferasirox was started on January 21st 2007 with a dose of $20 \mathrm{mg} / \mathrm{kg}$. Side effects were mild and included anorexia, nausea, abdominal cramps, diarrhoea and weight loss. On July 28th, the ferritin level was decreased to $507 \mu \mathrm{g} / \mathrm{l}$, and the liver enzyme levels had normalised. Fatigue was no longer present. Treatment with deferasirox was stopped, and the ferritin level and liver enzymes are regularly being monitored.

The prevalence of pyruvate kinase deficiency is $1 / 20,000$. The degree of haemolysis is variable, but iron overload is common, even in non-transfused patients [2]. The observation of effective iron removal and improvement of liver function tests in our patient suggests that iron chelation with deferasirox may be considered in patients with pyruvate kinase deficiency and severe iron overload.

Funding and conflicts of interest None to declare.

\section{References}

1. Metzgeroth G, Dinter D, Schultheis B, Dorn-Beineke A, Lutz K, Leismann $O$ et al (2008) Deferasirox in MDS patients with transfusion-caused iron overload-a phase-II study. Ann Hematol (in press). PMID: 18758781

2. Zanella A, Bianchi P, Fermo E (2007) Pyruvate kinase deficiency. Haematologica 92:721-723 doi:10.3324/haematol.11469

D. Deeren $(\bowtie)$

Department of Haematology,

Heilig-Hartziekenhuis Roeselare-Menen vzw,

Wilgenstraat 2,

B-8800 Roeselare, Belgium

e-mail: DDeeren@hhr.be 